\title{
A IMPORTÂNCIA DA PALMEIRA Syagrus coronata (Mart.) Beec. PARA A CONSERVAÇÃO DA RIQUEZA E DIVERSIDADE DE ESPÉCIES EPÍFITAS VASCULARES NA CAATINGA ${ }^{1}$
}

\author{
Raphaela Aguiar de Castro ${ }^{2 *}$, Juliano Ricardo Fabricante ${ }^{3}$ e José Alves de Siqueira Filho ${ }^{4}$
}

\footnotetext{
${ }^{1}$ Recebido em 31.01.2013 aceito para publicação em 30.10.2015.

${ }^{2}$ Universidade Federal do Vale do São Francisco, UNIVASF, Graduanda em Engenharia Agronômica, Petrolina, PE - Brasil. E-mail:<rapha.aguiarcastro@hotmail.com>.

${ }^{3}$ Universidade Federal de Sergipe, Doutorado em Agronomia, Itabaiana, Sergipe - Brasil. E-mail: <julianofabricante@hotmail.com>.

${ }^{4}$ Fundação Universidade Federal do Vale do São Francisco, Doutorado em Biologia Vegetal, Petrolina, Pernambuco - Brasil. E-mail: <jose.siqueira@univasf.edu.br>.

* Autor para correspondência.
}

\begin{abstract}
RESUMO - Neste estudo, o objetivo foi avaliar as diferenças entre a riqueza e a diversidade epifítica sobre os forófitos de licuri, Syagrus coronata (Mart.) Beec., e outras espécies da Caatinga, bem como verificar a maior frequência das epífitas sobre os estratos de $S$. coronata. O estudo foi realizado no Parque Nacional do Vale do Catimbau, em Pernambuco. Foram selecionados, aleatoriamente, 50 indivíduos adultos de $S$. coronata (L), assim como o indivíduo arbóreo adulto mais próximo de cada $S$. coronata $(\mathrm{O})$, excluindo-se os indivíduos de licuri, para contabilizar o número de indivíduos epifíticos por espécie e classificá-los quanto à forma de vida em hemepífitas primárias, hemepífitas secundárias, holoepífitas obrigatórias, holoepífitas facultativas e holoepífitas acidentais. Foram amostrados 760 indivíduos epifíticos distribuídos em 16 espécies, dos quais 15 táxons sobre $S$. coronata, principalmente encontrados na região da estipe recoberta pelos restos das bainhas das folhas antigas, e cinco no outro grupo forofítico. A diversidade de Shannon-Weaver (L - 1,936; O - 0,155) foi significativamente maior sobre $S$. coronata quando comparada com aquela observada sobre as outras espécies forofíticas. A análise de dissimilaridade florística das espécies epífitas em razão dos dois tipos de forófitos $(\mathrm{L} \mathrm{e} \mathrm{O})$ apontou a formação de agrupamentos mais consistentes entre os indivíduos de $S$. coronata em relação às demais espécies. Além disso, considerando os tamanhos do diâmetro à altura do solo (DAS) e a altura, evidenciou-se que, quanto maiores esses parâmetros, maiores também a riqueza e abundância de indivíduos epifíticos. Assim, este estudo corrobora a importância desta espécie como hospedeira da riqueza e diversidade epifítica na Caatinga e para a conservação das populações de S. coronata.
\end{abstract}

Palavras-chave: Epifitismo; PARNA do Catimbau; Arecaceae.

\section{THE IMPORTANCE OF THE PALM Syagrus coronata (Mart.) Beec. FOR THE CONSERVATION OF SPECIES RICHNESS AND DIVERSITY OF VASCULAR EPIPHYTES IN THE CAATINGA}

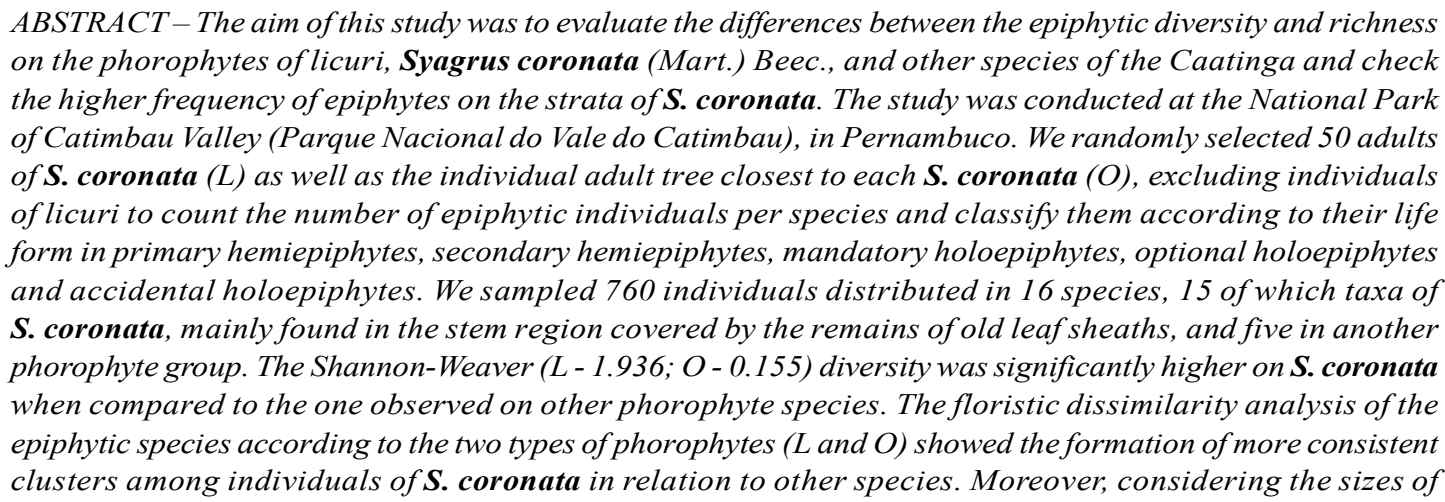


DGH (diameter at ground height) and height, it is evident that the higher these parameters are, the greater the richness and abundance of epiphytic individuals. Thus, this study confirms the importance of this species as a host of epiphytic diversity and richness in the Caatinga, and for the conservation of $\boldsymbol{S}$. coronata populations.

Keywords: Epiphytism; PARNA Catimbau; Arecaceae.

\section{INTRODUÇÃO}

As epífitas, grupo de plantas de grande importância ecológica, estão distribuídas em 84 famílias e aproximadamente 25.000 espécies, representando $10 \%$ de toda a flora vascular conhecida (KRESS, 1986; LÜTTGE, 1997). São fontes de recursos alimentares, como frutos, néctar, pólen e água, além de servirem de abrigo e local de reprodução de algumas espécies de animais (NADKARNI, 1988; SCHINEIDER; TEIXEIRA, 2001; MESTRE et al., 2001), possibilitando, assim, a ocorrência de uma diversidade faunística maior no ambiente que habitam (WAECHTER, 1992; MARQUES; FORATTINI, 2008). As epífitas também possuem grande influência na ciclagem de água e nutrientes nas florestas (INGRAM; NADKARNI, 1993; OLIVEIRA, 2004).

A despeito da sua importância, os estudos em florestas secas com esse grupo de plantas são escassos. Destacam-se os estudos desenvolvidos no Brasil (SILVA et al., 2006), no Equador (GENTRY; DODSON, 1987a), no Peru (IBISCH et al., 1996) e no México (OLMSTED; G'OMEZ-JU'AREZ, 1996; MONTANA et al., 1997; GARCÍA-SUÁREZ et al., 2003; MONDRAGÓN, 2004).

Trabalhos com as epífitas são mais abundantes em regiões tropicais e subtropicais úmidas (AGUIAR et al., 1981; GENTRY; DODSON, 1987b; COXSON; NADKARNI, 1995; ANDRADE; NOBEL, 1997; GUEVARA et al., 1998; NIEDER et al., 2001), incluindo o Brasil (CERVI; DOMBROWSKI, 1985; CERVI et al., 1988; PINTO et al., 1995; DISLICH, 1996; FONTOURA et al., 1997; WAECHTER, 1986, 1992, 1998; LABIAK; PRADO, 1998; DITTRICH et al., 1999; PILIACKAS et al., 2000; KERSTEN; SILVA, 2001; BATAGHIN et al., 2012; DUARTE; GANDOLFI, 2013; LEITMAN et al., 2014). Dessa forma, a base do conhecimento sobre as epífitas é dada em geral por estudos realizados em regiões úmidas. Esses autores demonstraram, por exemplo, a baixa frequência das epífitas vasculares em forófitos específicos (HIETZ, 1997; BONNET; QUEIROZ, 2006; BATAGHIN, 2009).

Revista Árvore, Viçosa-MG, v.40, n.1, p.1-12, 2016
A hipótese deste estudo é de que essa característica não se aplica às florestas secas com a presença da palmeira Syagrus coronata, espécie que possui estipe recoberto por pecíolos foliares e persistem após a queda das folhas mais velhas. Essas estruturas formam microssítios capazes de armazenar matéria orgânica e umidade (DRUMOND, 2007), o que se supõe favorecer a germinação de sementes e recrutamento de plântulas de epífitas (OLIVEIRA et al., 2015).

Essas bainhas das folhas antigas, em geral, não são encontradas nas demais espécies arbóreas das Caatingas, o que pode ser o fator de diferenciação entre a riqueza e a diversidade de espécies de epífitas sobre $S$. coronata em relação às outras espécies de forófitos. Dessa forma, a outra hipótese testada é de que existem estratos (regiões) específicos em $S$. coronata que favorecem o estabelecimento da comunidade epífita.

Os objetivos deste estudo foram: (i) avaliar comparativamente a riqueza e diversidade de espécies epífitas sobre a palmeira $S$. coronata e sobre outras espécies arbóreas da Caatinga; e (ii) verificar a frequência das epífitas sobre $S$. coronata por estratos de fixação. Adicionalmente, também foram avaliados outros aspectos ecológicos da relação entre as epífitas e $S$. coronata (análise de dissimilaridade florística da comunidade epífita e correlação dos parâmetros biométricos dos forófitos com a abundância e riqueza epifítica), a fím de nortear estratégias de conservação das espécies.

\section{MATERIAL E MÉTODOS}

\section{1. Área de estudo}

O estudo foi realizado no Parque Nacional do Vale do Catimbau (PARNA do Catimbau) (08³2'54,2" S; $037^{\circ} 14^{\prime} 49,6^{\prime \prime} \mathrm{W}$ ) (Figura 1). O Parque possui uma área de 62.300 hectares e está situado nos Municípios de Buíque, Ibimirim e Tupanatinga.

O PARNA do Catimbau é considerado de extrema importância biológica e área prioritária para a conservação da Caatinga, por apresentar números relevantes de endemismos e espécies raras (MMA, 2002; SAMPAIO 
et al., 2002), sendo considerado ainda o segundo maior sítio arqueológico do país. Apresenta flora diversificada, em que se encontram desde espécies características das Caatingas até espécies de áreas mais úmidas e de maior altitude, como Mata Atlântica, Campo Rupestre e Cerrado (RODAL et al., 1998). O local possui clima Tropical Semiárido com temperatura média anual de $26^{\circ} \mathrm{C}$, precipitação média anual de $600 \mathrm{~mm}$, estação chuvosa entre os meses de abril e junho e altitude entre 600-1.000 m (SUDENE, 1990; IBAMA, 2005).

A área de estudo possui por volta de $4 \mathrm{~km}^{2}$. É um setor do PARNA do Catimbau caracterizado pela Caatinga Arenícola, terrenos fortemente ondulados com grandes paredões, solos arenosos e altitude variando entre 800-1.000 m. A espécie distribui-se unicamente nessa região do Parque. Sua dispersão é irregular nessa área, apresentando manchas ora com elevado número de indivíduos, ora com poucos espécimes e indivíduos isolados entre eles (Figura 1).

\subsection{Metodologia}

Para avaliar as diferenças entre a riqueza e a diversidade epifítica sobre os forófitos de $S$. coronata e outras espécies arbóreas da Caatinga, foram selecionados 50 indivíduos adultos de $S$. coronata (L.), assim como o indivíduo arbóreo adulto mais próximo de cada $S$. coronata $(\mathrm{O})$, excluindo-se outros indivíduos de licuri, num total de 100 forófitos (unidades amostrais).

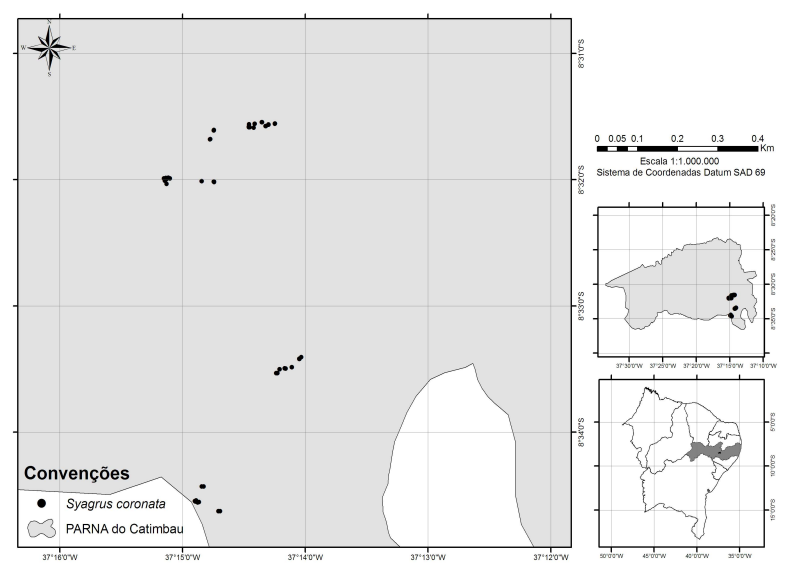

Figura 1 - Mapa de distribuição dos forófitos amostrados no Parque Nacional do Vale do Catimbau, Pernambuco.

Figure 1-Map of distribution of the sampled phorophytes in the National Park of Catimbau Valley, Pernambuco.
Foram considerados indivíduos adultos de $S$. coronata aqueles que apresentavam material reprodutivo ou restos deste. Já para os espécimes do outro grupo forofítico foram considerados adultos os indivíduos com DAS $\geq 3 \mathrm{~cm}$ (diâmetro à altura do solo) (adaptado de RODAL et al., 1992). Todos os forófitos tiveram aferidos seu DAS e estimada a sua altura total.

Em cada forófito foi contabilizado o número de indivíduos epifíticos por espécie. Aquelas espécies que possuem crescimento clonal, devido à sua reprodução vegetativa, foram considerados como um indivíduo, cada agrupamento (DISLICH, 1996). As epífitas foram classificadas quanto à sua forma de vida em hemiepífitas primárias, hemiepífitas secundárias, holoepífitas obrigatórias, holoepífitas facultativas e holoepífitas acidentais (BENZING, 1990). Por serem essencialmente terrícolas, as espécies desta última forma de vida foram desconsideradas neste estudo, evitando, assim, superestimavas do componente epifítico.

A diversidade epifítica foi avaliada segundo o índice de Shannon-Weaver $\left(H^{\prime}\right)$ (SHANNON; WEAVER, 1949) e a equabilidade de Pielou (E) (PIELOU, 1977).

O número mediano de indivíduos e espécies foi comparado entre os grupos de forófitos por meio do teste de Mann-Whitney (U) ( $p \leq 0,05)$ (ZAR, 1999). Diferenças entre as diversidades foram verificadas pelo teste $\mathrm{t}(p \leq 0,05)($ LEHMANN, 1997).

A dissimilaridade florística entre os forófitos foi verificada pelo coeficiente de distância de Bray-Curtis (BRAY-CURTIS, 1957), sendo testada a validade dos agrupamentos formados por meio do teste de permutação ANOSIM (oneway) (CLARKE, 1993). Através da SIMPER (porcentagem de similaridade), foi definido o percentual de contribuição das espécies epífitas para a formação dos grupos forofíticos (CLARKE, 1993). Na construção dos clusters, os indivíduos vazios (sem a presença de epífitas) foram suprimidos para melhorar a apresentação gráfica dos resultados. O método de agrupamento utilizado nessas analises foi o Arithmetic Average Clustering (SNEATH; SOKAL, 1973).

Visando verificar se os forófitos (unidades amostrais) espacialmente próximos são mais semelhantes floristicamente entre si (dependência espacial), foi realizado o teste de Mantel com 10.000 randomizações (MANTEL, 1967). Para tanto, foram correlacionadas duas matrizes de dissimilaridade, sendo uma de distância florística (Bray-Curtis) e outra de distância espacial

Revista Árvore, Viçosa-MG, v.40, n.1, p.1-12, 2016

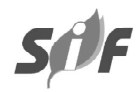


(distância euclidiana). A distância entre os forófitos foi aferida por meio de pontos de georreferenciamento obtidos com um aparelho de GPS.

Para inferir sobre a existência de sítios mais adequados para o estabelecimento das epífitas, os forófitos de $S$. coronata foram divididos em três estratos: (i) fuste - região que compreende a estipe da altura do solo até o início da região seguinte; (ii) transição - região da estipe recoberta pelos restos das bainhas das folhas antigas até o início da região seguinte; e (iii) copa - região apical caracterizada pelas folhas inseridas no ápice da estipe (Figura 2). A abundância de indivíduos e de espécies foi comparada entre os estratos, por meio do teste de Kruskal-Wallis (H) $(p \leq 0,05)$, com as diferenças entre os postos avaliadas por Dunn $(p \leq 0,05)$ (ZAR, 1999).

Fotografia: A. Popovikin. Photography: A. Popovikin.

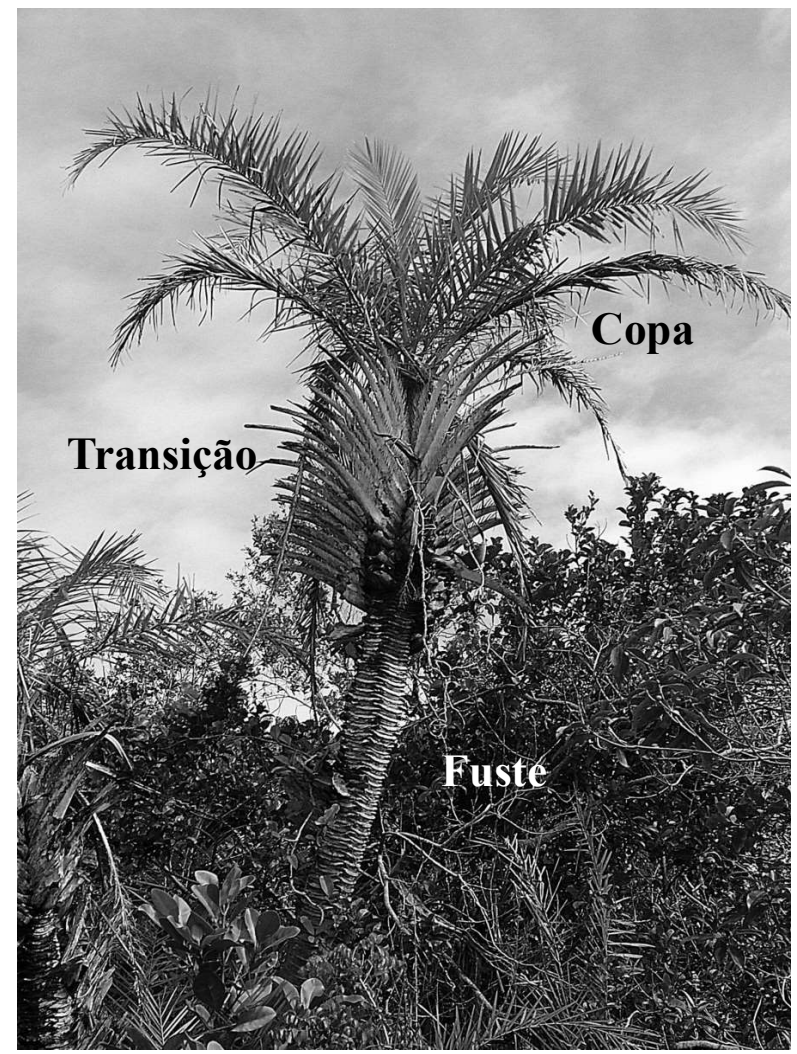

Figura 2 - Esquema da divisão dos indivíduos de Syagrus coronata em estratos.

Figure 2-Scheme of the division of Syagrus coronata individuals into strata.

Revista Árvore, Viçosa-MG, v.40, n.1, p.1-12, 2016
Para verificar se existe correlação entre o número de indivíduos e de espécies epifíticas e os parâmetros biométricos (DAS e altura) de $S$. coronata, utilizou-se o coeficiente de correlação de Pearson (r) (RODGERS; NICEWANDER, 1988), sendo sua significância avaliada pelo teste $\mathrm{t}(\mathrm{p} \leq 0,05)$ (LEHMANN, 1997).

Todas as espécies foram coletadas, herborizadas e incorporadas ao Herbário Vale do São Francisco (HVASF). A classificação taxonômica foi elaborada de acordo com o Sistema APG III (2009). As análises estatísticas foram executadas utilizando os softwares Past $1.15^{\circ}$ (HAMMER et al., 2001), MVSP $3.1^{\circ}$ (KOVACH, 2005) e BioEstat $5.0^{\circ}$ (AYRES et al., 2007).

\section{RESULTADOS}

Foram amostrados 760 indivíduos epifíticos distribuídos em 16 espécies, dos quais 202 espécimes e 15 táxons sobre $S$. coronata (L) e 558 indivíduos e cinco espécies, no outro grupo forofítico $(\mathrm{O})$, representados por 28 morfotipos, distribuídos em 15 famílias (Tabela 1).

Entre os 50 licuris observados, todos serviram de suporte para as epífitas e apenas 16 indivíduos dos demais forófitos tiveram a presença de alguma espécie epifítica. O valor mediano do número de espécies e de indivíduos foi maior sobre $S$. coronata (espécies $-\mathrm{L}=2 ; \mathrm{O}=0$; indivíduos $-\mathrm{L}=3 ; \mathrm{O}=0$ ), e ambas as variáveis apresentaram diferenças significativas entre os grupos forofíticos (espécies $-U=306 ; Z=6,51$; $\mathrm{p}<0,0001$; e indivíduos $-\mathrm{U}=561,5 ; \mathrm{Z}=4,75 ; \mathrm{p}<$ 0,0001).

Entre as formas de vida consideradas neste estudo, houve predominância das holoepífitas obrigatórias e facultativas, ambas representadas por sete espécies $(43,75 \%)$. Ainda foram encontradas duas hemiepífitas secundárias (12,5\%). Apesar de suprimida das análises, 38 morfotipos terrícolas foram encontrados sobre $S$. coronata, porém apenas três deles apresentavam material reprodutivo, indicando ser as únicas holoepífitas acidentais de fato: Alternanthera sp., Gomphrena sp.1 e Gomphrena sp.2, todas da família Amaranthaceae.

A diversidade também foi diferente entre os grupos de forófitos $(\mathrm{t}=21,3 ; \mathrm{p}<0,0001)$, sendo o $H^{\prime}$ ' epifítico estatisticamente maior sobre $S$. coronata $\left(\mathrm{L}-H^{\prime}=\right.$ 1,$\left.936 ; \mathrm{O}-H^{\prime}=0,155\right)$. O valor de $\mathrm{E}$ foi de 0,715 sobre $S$. coronata e de 0,096 sobre as outras espécies. 
Tabela 1 - Famílias e espécies epífitas amostradas no Parque Nacional do Vale do Catimbau, Pernambuco. Formas de vida segundo a classificação proposta por Benzing (1990) e abundância de indivíduos nos grupos forofíticos. Sendo: $\mathrm{L}$ - Syagrus coronata; e $\mathrm{O}$ - outras espécies.

Table 1 - Families and epiphytic species sampled in National Park of Catimbau Valley, Pernambuco. Life forms according to the classification proposed by Benzing (1990), and plenty of individuals in phorophyte groups. Where: $L$ - Syagrus coronata, $O$ - other species.

\begin{tabular}{|c|c|c|c|}
\hline \multirow[t]{2}{*}{ Família/Espécie } & \multirow[t]{2}{*}{ Forma de vida } & \multicolumn{2}{|c|}{ Forófito } \\
\hline & & $\mathrm{L}$ & $\mathrm{O}$ \\
\hline \multicolumn{4}{|l|}{ Araceae } \\
\hline Anthurim petrophilum $\mathrm{K}$. Krause & Holoepífita facultativa & 2 & - \\
\hline Anthurium sp. & Holoepífita facultativa & 3 & - \\
\hline Philodendrum acutatum Schott. & Hemiepífita secundária & 3 & 1 \\
\hline \multicolumn{4}{|l|}{ Begoniaceae } \\
\hline Begonia sp. & Holoepífita facultativa & 4 & - \\
\hline \multicolumn{4}{|l|}{ Bromeliaceae } \\
\hline Aechmea leptantha (Harms) Leme \& J.A. Siqueira & Holoepífita facultativa & 10 & - \\
\hline Billbergia porteana Linneu & Holoepífita facultativa & 38 & - \\
\hline Tillandsia catimbauensis Leme, W. Till \& J.A. Siqueira & Holoepífita facultativa & 9 & 5 \\
\hline Tillandsia loliacea Mart. ex Schult. \& Schult.f. & Holoepífita obrigatória & 2 & 2 \\
\hline Tillandsia recurvata (L.) L. & Holoepífita obrigatória & 25 & 543 \\
\hline Tillandsia streptocarpa Baker & Holoepífita obrigatória & - & 7 \\
\hline \multicolumn{4}{|l|}{ Orchidaceae } \\
\hline Catasetum purum Nees \& Sinnings & Holoepífita obrigatória & 75 & - \\
\hline Vanilla palmarum (Salzm. ex Lind1.) Lindl. & Hemiepífita secundária & 24 & - \\
\hline \multicolumn{4}{|l|}{ Piperaceae } \\
\hline Peperomia sp. & Holoepífita obrigatória & 1 & - \\
\hline \multicolumn{4}{|l|}{ Polypodiaceae } \\
\hline Pleopeltis polypodiodes (L.) Andrews \& Windham & Holoepífita obrigatória & 3 & - \\
\hline Serpocaulon triseriale (Sw.) A.R.Sm. & Holoepífita obrigatória & 2 & - \\
\hline Pteridaceae sp. & Holoepífita facultativa & 1 & - \\
\hline Total & & 202 & 558 \\
\hline
\end{tabular}

A análise de dissimilaridade mostrou a formação de agrupamentos mais consistentes (com menor valor de Bray-Curtis) entre os indivíduos de S. coronata. Também, verificou-se alta dissimilaridade desse grupo com os indivíduos das outras espécies (Figura 3). Segundo o teste de permutação ANOSIM, o valor de $\mathrm{R}$ foi de $0,47(\mathrm{p}<0,0001)$, indicando que as réplicas dentro dos grupos forófitos são mais similares entre si do que com as repetições do outro grupo.

Duas Orchidaceae e duas Bromeliaceae foram as espécies que mais contribuíram para a formação dos grupos forofíticos, segundo a SIMPER. Catasetum purum foi o táxon com maior porcentagem de contribuição (37,70\%), seguido por Tillandsia recurvata $(20,93 \%)$, Vanilla palmarum $(12,06 \%)$ e Bilbergia porteana $(11,01 \%)$. As outras 12 espécies contribuíram com $18,30 \%$.

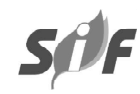

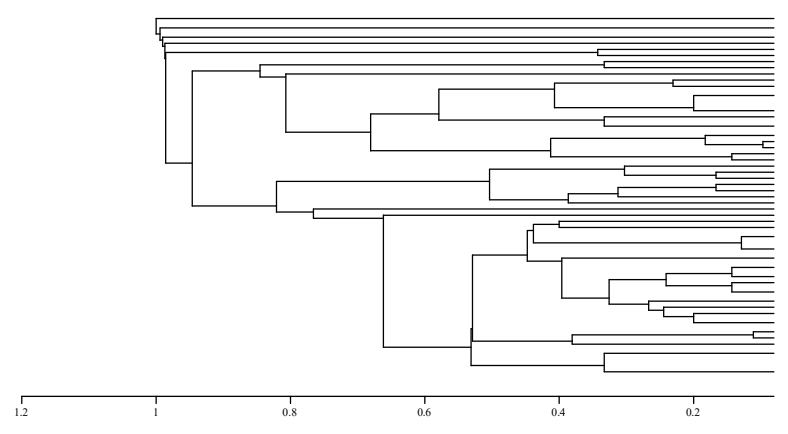

Figura 3 - Cluster produzido pela análise de Bray-Curtis para os forófitos amostrados no Parque Nacional do Vale do Catimbau, Pernambuco. Sendo: $\mathrm{L}_{\mathrm{n}-1}-$ Syagrus coronata; $\mathrm{O}_{\mathrm{n}-1}$ - outras espécies.

Figure 3 - Cluster analysis of Bray-Curtis for phorophytes sampled at National Park of Catimbau Valley, Pernambuco. Where: $L_{n-1}$-Syagrus coronata; and $O_{n-1}-$ other species.

Revista Árvore, Viçosa-MG, v.40, n.1, p.1-12, 2016 
A similaridade florística apresentou dependência espacial segundo o teste de Mantel $(\mathrm{R}=0,074 ; \mathrm{p}=$ $0,025)$, ou seja, que os forófitos espacialmente mais próximos são mais semelhantes floristicamente entre si do que daqueles mais distantes.

Apenas um indivíduo de uma única espécie foi amostrado na copa de $S$. coronata. Os demais se distribuíram entre o fuste (nove espécies e 61 indivíduos) e a transição (13 espécies e 140 indivíduos) (Tabela 2). As diferenças observadas foram comprovadas estatisticamente (espécies $-\mathrm{H}=59,87 ; \mathrm{p}<0,0001$; indivíduos $-\mathrm{H}=59,28 ; \mathrm{p}<0,0001)$, sendo ambas maiores na transição.

Os números de indivíduos e de espécies epífitas apresentaram correlação positiva com diâmetro e altura de $S$. coronata. Dessa forma, ficou caracterizado que quanto maior o DAS e a altura dos forófitos, maior a riqueza de espécies (DAS $-\mathrm{r}=0,2965 ; \mathrm{t}=2,15 ; \mathrm{p}=0,0365$; altura $-\mathrm{r}=0,3851 ; \mathrm{t}=2,89 ; \mathrm{ep}=0,0057$ ) e abundância de indivíduos $(\mathrm{DAS}-\mathrm{r}=0,3274 ; \mathrm{t}=2,4 ; \mathrm{p}=0,0202 ;$ altura $-\mathrm{r}=0,4482$; $\mathrm{t}=3,47$; e $\mathrm{p}=0,0011)$ epifíticos.

\section{DISCUSSÃO}

A riqueza de espécies epífitas no PARNA do Catimbau foi menor que a da maioria das áreas estudadas no eixo Sul-Sudeste do país: Na Ilha do Mel, em Paranaguá (PR), Kersten e Silva (2001) encontram 77 espécies epífitas distribuídas na Restinga e na Floresta Ombrófila Densa local. Nos Municípios de Terra de Areia e Capão da Canoa, na planície litorânea do Rio Grande do Sul, em Florestas Arenosas, Turfosas e Pluviais, também foram observadas 77 espécies epifíticas (GONÇALVES; WAECHTER, 2002). No Município de Assis, SP, em uma área de Savana, em Sete Barras (SP) em um sítio de Floresta Ombrófila Densa, em Cananeia (SP) na Restinga e em Galia (SP), em uma Floresta Estacional Semidecidual, foram observadas $15,161,178$ e 25 espécies epífitas, respectivamente (BREIER, 2005). Na região Oeste do Estado do Paraná, em uma área de Floresta Estacional Semidecidual e em uma de Floresta Ombrófila Mista, Cervi e Borgo (2007) encontram 56 espécies. Geraldino et al. (2010), na mesorregião Centro Ocidental do Paraná, em um sítio de Floresta Estacional Semidecidual, e de Floresta Ombrófila Mista, observaram 61 espécies de epífitas vasculares. Bianchi et al. (2012), em região de transição de Floresta Ombrófila Mista e para a Floresta Ombrófila Densa, registraram 127 espécies epifíticas.

Dias-Terceiro (2010), em um fragmento de Floresta Ombrófila Aberta no Nordeste brasileiro, amostrou 23 táxons. Na Caatinga, em área antropizada no Estado da Bahia, estudo de epífitas realizado também em licuri demonstra a presença de 18 espécies epífitas, porém distribuídas em número menor de famílias que o deste estudo (seis) (OLIVEIRA et al., 2015).

Tabela 2 - Número de indivíduos das espécies epífitas sobre S. coronata amostrados no Parque Nacional do Vale do Catimbau, Pernambuco.

Table 2 - Number of individuals of species epiphytes on S. coronata sampled at Valley National Park Catimbau, Pernambuco.

\begin{tabular}{|c|c|c|c|}
\hline \multirow[t]{2}{*}{ Espécie } & \multicolumn{3}{|c|}{ Estratos } \\
\hline & Fuste & Transição & Copa \\
\hline Aechmea lepthanta & - & 10 & - \\
\hline Anthurim petrophilum & 1 & 1 & - \\
\hline Anthurium sp. & - & 3 & - \\
\hline Begonia sp. & - & 4 & - \\
\hline Billbergia porteana & 9 & 29 & - \\
\hline Catasetum purum & 12 & 62 & 1 \\
\hline Peperomia sp. & - & 1 & - \\
\hline Philodendrum acutatum & 2 & 1 & - \\
\hline Pleopeltis polypodiodes & 2 & 1 & - \\
\hline Pteridaceae sp. & - & 1 & - \\
\hline Serpocaulon triseriale & - & 2 & - \\
\hline Tillandsia catimbauensis & 9 & - & - \\
\hline Tillandsia loliaceae & 2 & - & - \\
\hline Tillandsia recurvata & 21 & 4 & - \\
\hline Tillandsia streptocarpa & - & - & - \\
\hline Vanilla palmarum & 3 & 21 & - \\
\hline Total & 61 & 140 & 1 \\
\hline
\end{tabular}

Revista Árvore, Viçosa-MG, v.40, n.1, p.1-12, 2016 
As famílias com maior número de espécies são as mesmas, havendo o predomínio das bromeliáceas e orquidáceas. Essas famílias possuem grande quantidade de espécies e indivíduos nas fisionomias florestais dos neotrópicos (WAECHTER, 1998), o que parece só se repetir em Caatinga com a presença de Syagrus coronata. Em uma área dessa formação savânica sem a palmeira, Silva et al. (2006) só encontraram Bromeliaceae, sendo todos táxons atmosféricos (BENZING; RENFROW, 1980; BENZING, 1990; LEME, 1993), os mesmos observados no grupo forofítico das demais espécies neste estudo.

Diferentemente do que ocorre em florestas úmidas onde há a predominância de holoepífitas obrigatórias (GONÇALVES; WAECHTER, 2003; MANIA, 2008; DIAS, 2009; GERALDINO et al., 2010; MANIA; MONTEIRO, 2010), no PARNA do Catimbau, as holoepífitas facultativas apresentaram a mesma proporção de espécies dessa outra forma de vida. As condições biofísicas das Caatingas como intensa radiação solar em todo o gradiente solotopo das árvores, baixo porte da vegetação e solos bem drenados, são em conjunto com as prováveis razões para esse resultado e corroboram com o que foi apontado por Waechter(1998) e Kersten e Silva (2001), para explicar a grande contribuição desse grupo nas áreas estudadas pelos autores.

Conforme Callaway et al. (2002), quanto mais xérico o ambiente, maior a importância da morfologia dos forófitos, tornando a interação entre epífitas e hospedeiras mais espécie-específica. Os resultados deste estudo corroboram essa afirmação, pois sobre o forófito $S$. coronata, particularmente sobre as bainhas das folhas antigas, a flora epífita é composta por espécies exclusivas, e a riqueza e diversidade são maiores quando comparadas com o outro grupo forofítico.

O estabelecimento de epífitas está fortemente relacionado aos atributos individuais dos forófitos, como altura, diâmetro, idade, formato da copa, textura e química da casca(GENTRY; DODSON, 1987b; GARCIA-FRANCO; RICO-GRAY, 1988; DISLICH, 1996; HIETZ, 1997; FONTOURA etal., 1997; NIEDER etal., 2000). Em regiões semiáridas e áridas, estruturas morfológicas específicas devem ser mais relevantes, a exemplo das bainhas foliares e da copa perene das palmeiras. As bainhas favorecem o acúmulo de matéria orgânica e água e criam microhábitat com condições satisfatórias para a germinação de sementes e o recrutamento de plântulas (GRIME, 2001; PEARSON et al., 2002). A copa perene, por sua vez, ameniza as condições físicas abióticas desfavoráveis incidentes em ambientes mais abertos e secos (WERNECK; ESPÍRITO-SANTO, 2002).

Das quatro espécies mais importantes para a formação dos grupamentos na análise de dissimilaridade, três delas (Catasetum purum, Vanilla palmarum e Bilbergia porteana) ocorreram exclusivamente sobre $S$. coronata, reforçando a importância da palmeira como hospedeiro de epífitas na Caatinga. A outra espécie foi Tillandsia recurvata, cuja contribuição para a constituição dos grupos foi dada por sua ocorrência em ambos os grupos forofíticos. Essa bromeliácea é uma das epífitas com área de ocorrência mais ampla na América Tropical (VALVERDE et al., 2005), ocorrendo nos mais variados ambientes, desde os semiáridos mexicanos (VALVERDE et al., 2005) até as planícies costeiras úmidas do Rio Grande do Sul (GONÇALVES; WAECHTER, 2002), inclusive em sítios antropogênicos (FABRICANTE et al., 2006; PADILHA, 2010). Como a espécie é muito generalista e plástica, ocorre em todos os tipos de forófitos.

A dependência espacial da similaridade florística e a correlação positiva entre a riqueza e diversidade das epífitas com o DNS e altura dos forófitos indicam que, para que a riqueza e diversidade epifítica sejam mantidas na área, é necessário que várias subpopulações de $S$. coronata e os indivíduos mais velhos (maior DNS e altura) da espécie sejam preservados e manejados adequadamente. A despeito de ilegal (IBAMA, Instrução Normativa, $\mathrm{n}^{\circ} 191$, de 24 de setembro de 2008), S. coronata é uma das frutíferas mais exploradas de forma extrativista na Caatinga, o que tem levado a uma rápida diminuição das suas populações naturais (DRUMOND et al., 2000), especialmente aquelas mais velhas, que por sua vez possuem arquitetura mais propícia para a manutenção da diversidade epifítica.

\section{CONCLUSÃO}

Ambas as hipóteses testadas neste estudo foram aceitas. Assim, conclui-se que as epífitas apresentam maior riqueza e diversidade em forófito específico (Syagrus coronata) e pelo estrato de transição, que é composto pela região da estipe de $S$. coronata recoberta pelos restos das bainhas das folhas antigas. Esses resultados convergem para a importância da espécie $S$. coronata como amplificadora da riqueza e diversidade epifítica na Caatinga e para a importância da conservação das populações de $S$. coronata.

Revista Árvore, Viçosa-MG, v.40, n.1, p.1-12, 2016

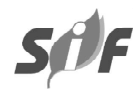




\section{AGRADECIMENTOS}

Ao Ministério da Integração Nacional e ao Sr. Francisco de Assis Araújo, chefe do PARNA do Catimbau.

\section{REFERÊNCIAS}

AGUIAR, L.W.; CITADINI-ZANETTE, V.; MARTAU, L.; BACKES, A. Composição florística de epífitos vasculares numa área localizada nos municípios de Montenegro e Triunfo, Rio Grande do Sul, Brasil. Iheringia Série Botânica, v.28, n.1, p.55-93, 1981.

ANDRADE; J.L.; NOBEL, P.S. Microhabitats and water relations of epiphytic cacti and ferns in a lowland neotropical forest. Biotropica, v.29, n.3, p.261-270, 1997.

AYRES, M.; AYRES JUNIOR, M.; AYRES, D.L.; SANTOS, A.A.S. BioEstat: aplicações estatísticas nas áreas de Ciências Biomédicas. Belém: Sociedade Civil Mamirauá, 2007. 334p.

BATAGHIN, F.A. Distribuição da comunidade de epífitos vasculares em diferentes sítios na Floresta Nacional de Ipanema, Iperó, SP, Brasil. 2009. $74 \mathrm{f}$. Dissertação (Mestrado em Ecologia) Universidade Federal de São Carlos, São Carlos, 2009.

BATAGHIN, F.A.; MULLER, A.; PIRES, J.S.R.; BARROS, F.; FUSHITA, A.T.; SCARIOT, E.C. Riqueza e estratificação vertical de epífitas vasculares na Estação Ecológica de Jataí: área de Cerrado no Sudeste do Brasil. Hoehnea, v.39, n.4, p.615-626, 2012.

BIANCHI, J.S.; BENTOS, C.M.; KERSTEN, R.A. Epífitas vasculares de uma área de ecótono entre as Florestas Ombrófilas Densa e Mista, no Parque Estadual do Marumbi, PR. Estudos de Biologia, v.34, p.37-44, 2012.

BENZING, D.H. Vascular epiphytes.

Cambrige: Cambrige University Press. 1990. 52p.

BENZING, D.H.; RENFROW, A. The nutritional dynamics of Tillandsia circinnata in Southern Florida and the origin of the "air plant" strategy. Botanical Gazette, v.141, n.2, p.165-172, 1980.
BONNET, A.; QUEIROZ, M.H. Estratificação vertical de bromélias epifíticas em diferentes estádios sucessionais da Floresta Ombrófila Densa, Ilha de Santa Catarina, Santa Catarina, Brasil. Revista Brasileira de Botânica, v.29, n.2, p.217-228, 2006.

BRAY, R.J.; CURTIS, J.T. An ordination of the upland forests communities of southern Winsconsin. Ecological Monographs, v.27, n.4, p.325-349, 1957.

\section{BREIER, T.B. O epifitismo vascular em} florestas do sudeste do Brasil. 2005. $104 \mathrm{f}$ Tese (Doutorado em Biologia Vegetal) Universidade Estadual de Campinas, Campinas, 2005.

CALLAWAY, R.M.; REINHART, K.O.; MOORE, G.W.; MOORE, D.J.; PENNINGS, S.C. Epiphyte host preferences and host traits: mechanisms for species-specific interactions. Oecologia, v.132, n.2, p.221-230, 2002.

CERVI, A.C.; ACRA, L.A.; RODRIGUES, L.; TRAIN, S.; IVANCHECHEN, S.L.; MOREIRA, A. Contribuição ao conhecimento das epífitas (exclusive Bromeliaceae) de uma floresta de araucária do primeiro planalto paranaense. Ínsula, v. 18, n.1, p.75-82, 1988 .

CERVI, A.C.; DOMBROWSKI, L.T.D. Bromeliaceae de um capão de floresta primária do Centro Politécnico de Curitiba (Paraná, Brasil). Fontqueria, v.9, n.1, p.9-11, 1985.

CERVI, A.C.; BORGO, M. Epífitos vasculares no Parque Nacional do Iguaçu, Paraná (Brasil). Levantamento preliminar. Fontqueria, v.55, n.51, p.415-422, 2007.

CLARKE, K.R. Non-parametric multivariate analysis of changes in community structure. Australian Journal of Ecology, v. 18, n.1, p.117-143, 1993.

COXSON, D.S.; NADKARNI, N.M. Ecological roles of epiphytes in nutrient cycles of forest ecosystems. In: LOWMAN, M.D.; NADKARNI, N.M. (Ed.). Forest canopies. San Diego: Academic Press, 1995. p.495-543. 
DIAS, A.S. Ecologia de epífitas vasculares em uma área de mata atlântica do Parque Nacional da Serra dos Órgãos, Teresópolis, RJ. 2009. 40 f. Dissertação (Mestrado em Ciências) Universidade Federal Rural do Rio de Janeiro, 2009.

DIAS-TERCEIRO, R.G. Distribuição espacial do componente epifítico vascular em um fragmento de floresta ombrófila aberta situado no município de Areia, PB. 2010. 30f. Monografia (Graduação em Ciências Biológicas) - Universidade Federal da Paraíba, Areia, 2010.

DISLICH, R. Florística e estrutura do componente epifítico vascular da Reserva da Cidade Universitária “Armando de Salles Oliveira”, São Paulo, Brasil. 1996. 29f. Dissertação (Mestrado em Ecologia) - Universidade de São Paulo, São Paulo, 1996.

DITTRICH, V.A.O.; KOZERA, C.; SILVA, S.M. Levantamento florístico de epífitos vasculares no Parque Barigüi, Paraná, Brasil. Iheringia Série Botânica, v.25, n.1, p.11-22, 1999.

DRUMOND, M.A.; KIILL, L.H.P.; LIMA, P.C.F.; OLIVEIRA, M.C.; OLIVEIRA, V.R.; ALBUQUERQUE, S.G.; NASCIMENTO, C.E.S.; CAVALCANTI, J. Avaliação e identificação de ações prioritárias para a conservação, utilização sustentável e repartição de benefícios da biodiversidade do bioma Caatinga. Petrolina: Embrapa Semi-Árido, 2000.3p.

\section{DRUMOND, M.A. Licuri Syagrus coronata} (Mart.) Becc. Petrolina: Embrapa Semi-Árido, 2007. 10p.

DUARTE, M.M.; GANDOLFI, S. Enriquecimento de florestas em processo de restauração: aspectos de epífitas e forófitos que podem ser considerados. Hoehnea, v.40, n.3, p.507-514, 2013.

FABRICANTE, J.R.; ANDRADE, L.A.; MARQUES, F.J. Componente epifítico vascular ocorrente em árvores urbanas. Cerne, v.12, n.4, p.399-405, 2006.

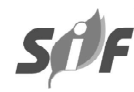

FONTOURA, T.; SYLVESTRE, L.S.; VAZ, A.M.S.; VIEIRA, C.M. Epífitas vasculares, hemiepífitas e hemiparasitas da Reserva Ecológica de Macaé de Cima. In: LIMA, H.C.; GUEDES-BRUNI, R.R. (Ed.). Serra de Macaé de Cima: diversidade florística e conservação em mata atlântica. Rio de Janeiro: Instituto de Pesquisas Jardim Botânico do Rio de Janeiro, 1997. p.89-101.

GARCÍA-SUÁREZ, M.A.; RICO-GRAY, V.; SERRANO, H. Distribution and abundance of Tillandsia spp. (Bromeliaceae) in the Zapotitlán Valley, Puebla, México. Plant Ecology, v.166, n.2, p.207-215, 2003.

GARCIA-FRANCO, J.G.; RICO-GRAY, V. Experiments on seed dispersal and deposition patterns of epiphytes - the case of Tillandsia deppeana Steudel (Bromeliaceae). Phytologia, v.65, n.1, p.73-78, 1998.

GENTRY, A.H.; DODSON C.H. Contribution of non-trees to species richness of a tropical rain forest. Biotropica, v.19, p.149-156, 1987a.

GENTRY, A.H.; DODSON C.H. Diversity and biogeography of neotropical vascular epiphytes. Annals of the Missouri Botanical Garden, v.74, n.1, p.205-223, 1987 b.

GERALDINO, H.C.L.; CAXAMBÚ, M.G.; SOUZA, D.C. Composição florística e estrutura da comunidade de epífitas vasculares em uma área de ecótono em Campo Mourão, PR, Brasil. Acta Botânica Brasilica, v.24, n.2, p.469-482, 2010.

GRIME, J.P. Plant strategies, vegetation processes, and ecosystem properties. 2 . ed. Chichester: Wiley, 2001. 14p.

GONÇALVES, C.N.; WAECHTER, J.L. Epífitos vasculares sobre espécimes de Ficus organensis isolados no norte da planície costeira do Rio Grande do Sul: padrões de abundância e distribuição. Acta Botanica Brasilica, v. 16, n.4, p.429-441, 2002.

GONÇALVES, C.N.; WAECHTER, J.L. Aspectos florísticos e ecológicos de epífitos vasculares sobre figueiras isoladas no norte da planície costeira do Rio Grande do Sul. Acta Botanica Brasilica, v. 17, n.1, p.89-100, 2003.

Revista Árvore, Viçosa-MG, v.40, n.1, p.1-12, 2016 
GUEVARA, L.; LABORDE, J.; SÁNCHEZ, G. Are isolated remmant trees in pastures a fragmented canopy? Selbyana, v.19, n.1, p.34-43, 1998.

HAMMER, O.; HAPER, D.A.T.; RYAN, P.D. PAST: Paleontological Statistics Software package for education and data analysis. Palaeontologia Electronica, v.4, n.1, p.9, 2001.

HIETZ, P. Population dynamics of epiphytes in a Mexican humid montane forest. Journal of Ecology, v.85, n.6, p.767-775, 1997.

\section{INSTITUTO BRASILEIRO DO MEIO AMBIENTE E} DOS RECURSOS RENOVÁVEIS - IBAMA.

Unidades de Conservação. 2005.

Disponível em: http://www.ibama.gov.br/supes-am/ unidades-de-conservacao. Acesso em: 20 abr. 2012.

IBISCH, P.L.; BOEGNER, A.; NIEDER, J.; BARTHLOTT, W. How diverse are neotropical epiphytes? An analysis based on the "Catalogue of the flowering plants and Gymnosperms of Peru". Ecotropica, v.2, n.1, p.13-28, 1996.

INGRAM, S.W.; NADKARNI, N.M. Composition and distribution of epiphytic organic matter in a Neotropical Cloud Forest, Costa Rica.

Biotropica, v.25, n.4, p.370-383, 1993.

\section{INSTITUTO BRASILEIRO DO MEIO AMBIENTE E} DOS RECURSOS RENOVÁVEIS - IBAMA.

Instrução normativa, $n^{0} 191$, de 24 de set. de 2008. Disponível em: http://

www.sema.mt.gov.br/

index.php?option $=$ com_content\&view $=$ article $\& i d=41$ 4\&Itemid=346 Acesso em: 19 jun. 2012.

KERSTEN, R.A.; SILVA, S.M. Composição florística e estrutura do componente epifítico vascular em Floresta da planície litorânea na Ilha do Mel, Paraná, Brasil. Revista Brasileira de Botânica, v.24, n.2, p.213-226, 2001.

KOVACH, W. L. MVSP - A multivariate statistical package for windows, ver. 3.1. Pentraeth: Kovach Computing Services, 2005. 133p.

KRESS, W.J. The systematic distribution of vascular epiphytes: an update. Selbyana, v.9, n. 1, p.2-22, 1986.

Revista Árvore, Viçosa-MG, v.40, n.1, p.1-12, 2016
LABIAK, P.H.; PRADO, J. Pteridófitas epífitas da Reserva Volta Velha, Itapoá - Santa Catarina, Brasil. Boletim do Instituto de Botânica, v.11, n.1, p.1-79, 1998

\section{LEHMANN, E.L. Testing statistical} hypotheses. 2. ed. New York: Springer-Verlag, 1997.600p.

LEITMAN, P.; AMORIM, A.; MENINI NETO, L.; FORZZA, R.C. Epiphytic angiosperms in a mountain forest in southern Bahia, Brazil. Biota Neotropica, v.14, n.2, p.1-12, 2014.

LEME, E.M.C.; MARIGO, L.C. Bromélias na natureza. Rio de Janeiro: Marigo Comunicação Visual, 1993. 12p.

LÜTTGE, U. Epiphytes, lianas and hemiepiphytes. In: LÜTTGE, U. (Ed.). Physiological ecology of tropical plants. Berlim: Springer-Verlag, 1997. p.210-224.

MANIA, L.F. Florística e distribuição de epífitas vasculares em floresta alta de restinga na planície litorânea da praia da fazenda, núcleo Picinguaba, Parque Estadual Serra do Mar, município de Ubatuba, SP. 2008. 63f. Dissertação (Mestrado em Ciências Biológicas) - Universidade Estadual Paulista, Rio Claro. 2008.

MANIA, L.F.; MONTEIRO, R. Florística e ecologia de epífitas vasculares em um fragmento de floresta de restinga, Ubatuba, SP, Brasil. Rodriguésia, v.61, n.4, p.705-713, 2010.

MANTEL, N. The detection of disease clustering and a generalized regression approach. Cancer Research, v.27, p.209-220, 1967.

MARQUES, G.R.A.M.; FORATTINI, O.P. Culicídeos em bromélias: diversidade de fauna segundo influência antrópica, litoral de São Paulo. Revista de Saúde Pública, v.42, p.979-985, 2008.

MESTRE, L.A.M.; ARANHA, J.M.R.; ESPER, M.L. Macroinvertebrate fauna associated to the bromeliad Vrisea inflata of Atlantic Forest (Parana state, southern Brazil). Brazilian Archives of Biology and Technology, v.44, n.1, p.89-94, 2001. 
BRASIL. Ministério do Meio Ambiente, dos Recursos Hídricos e da Amazônia Legal. Avaliação e ações prioritárias para conservação da biodiversidade da Caatinga. 2002. Disponível em: http:// www.mma.gov.br/biodiversidade/biodiversidadebrasileira/áreas-prioritárias. Acesso em: 25 ago. 2012.

MONDRAGÓN, D.; DURAN, R.; RAMÍREZ, I.; VALVERDE, T. Temporal variation in the demography of the clonal eiphyte Tillandsia brachycaulos (Bromeliaceae) in the Yucatán Peninsula, Mexico. Journal of Tropical Ecology, v.20, n.2, p.189-200, 2004.

MONTAÑA, C.; DIRZO, R.; FLORES, A. Structural parasitism of an epiphytic bromeliad upon Cercidium praecox in an intertropical semiarid ecosystem. Biotropica, v.29, n.4, p.517-521, 1997.

NADKARNI, N.M. Tropical rainforest ecology from a canopy perspective. In: ALMEIDA, F.; PRINGLE, C.M. (Ed.). Tropical rainforest: diversity and conservation. San Francisco: American Association for the Advancement of Science, 1988. p.306-308.

NIEDER, J.; ENGWALD, S.; KLAWUN, M.; BARTHLOTT, W. Spatial distribution of vascular epiphytes (including Hemiepiphytes) in a lowland amazonian rain forest (surumoni crane plot) of southern Venezuela. Biotropica, v.32, n.3, p.385-396, 2000 .

NIEDER, J.; PROSPERÍ, J.; MICHALOUD, G. Epiphytes and their contribution to canopy diversity. Plant Ecology, v.153, n.1, p.51-63, 2001.

OLIVEIRA, R.R. Importância das bromélias epífitas na ciclagem de nutrientes da Floresta Atlântica. Acta Botanica Brasilica, v. 18, n.4, p.793799, 2004.

OLIVEIRA, U.R.; ESPÍRITO-SANTO, F.S.; ALVAREZ, I.A. Comunidade epifítica de Syagrus coronata (mart.) becc. (Arecaceae) em áreas de pastagens na Caatinga, Bahia. Revista Caatinga, v.28, n.2, p.84-91, 2015.

OLMSTED, I.; JUÁREZ, M.G. Distribution and conservation of epiphytes on the Yucatan Peninsula. Selbyana, v. 17, n. 1, p.58-70, 1996.
PADILHA, P.T. Comunidade de bromélias epifíticas em fragmento urbano de Floresta Ombrófila Densa em Criciúma, Santa Catarina. 2010. $21 \mathrm{f}$. Trabalho de Conclusão de Curso (Graduação em Ciências Biológicas) - Universidade do Extremo Sul Catarinense, Criciúma, 2010.

PEARSON, T.R.H.; BURSLEM, D.F.R.P.; MULLINS, C.E.; DALLING, J.W. Germination ecology of neotropical pioneers: interacting effects of environmental conditions and seed size. Ecology, v.83, p.2798-2807, 2002.

PIELOU, E.C. Mathematical ecology. New York: John Wiley \& Sons, 1977. 385p.

PILIACKAS, J.M.; BARBOSA, L.M.; CATHARINO, E.L.M. Levantamento das epífitas vasculares do manguezal do Rio Picinguaba, Ubatuba, São Paulo. In: SIMPÓSIO DE ECOSSISTEMAS BRASILEIROS, 5., 2000, São Paulo. Anais... São Paulo: ACIESP, 2000. v.2. p.357-363

PINTO, A.C.; DEMATTÊ; M.E.S.P.; PAVANI, M.C.M.D. Composição florística de epífitas (Magnoliophyta) em fragmento de floresta no município de Jaboticabal, SP, Brasil. Científica, v.23, n.2, p.283-289, 1995.

RODAL, M.J.N.F.; SAMPAIO, E.V.S.B.; FIGUEIREDO, M.A. Manual sobre métodos de estudos florísticos e

fitossociológicos: ecossistema caatinga. Brasília: Sociedade Botânica do Brasil, 1992. 24p.

RODAL, M.J.N.; ANDRADE, K.V.A.; SALES, F.M.; GOMES, A.P.S. Fitossociologia do componente lenhoso de um refúgio vegetacional no município de Buíque, Pernambuco. Revista Brasileira de Biologia, v.58, n.3, p.517-526, 1998.

RODGERS, J.L.; NICEWANDER, W.A. Thirteen ways to look at the correlation coefficient. The American Statistician, v.42, n.1, p.59-66, 1988.

SAMPAIO, E.V.S.B. Uso das plantas da caatinga. In: SAMPAIO, E.V.S.B.; GIULIETTI, A.M.; VIRGÍNIO, J.; GAMARRA-ROJAS, C. (Ed.). Vegetação e flora da caatinga. Recife: APNE/CNIP, 2002. p.49-90.

Revista Árvore, Viçosa-MG, v.40, n.1, p.1-12, 2016 
SCHINEIDER, J.A.P.; TEIXEIRA, R.L.

Relacionamento entre anfíbios anuros e bromélias da restinga de regência, Linhares, Espírito Santo, Brasil. Iheringia, Série Zoológica, v.91, p.41-48, 2001.

SHANNON, C.E.; WEAVER, W. The mathematical theory of communication. Urbana: University of Illinois Press, 1949. 117p.

SILVA, M.A.P.; BARROS, L.M.; ALENCAR, A.L.; BRAGA, M.R.; FERREIRA, J.K.A.; SANTOS, A.C.B. Cadernos de Cultura e Ciência, v. 1, n.1, p.22-25, 2006.

SNEATH, P.H.A.; SOKAL, R.R. Numerical taxonomy. San Francisco: Freeman, 1973. 573p.

SUPERINTENDÊNCIADO DESENVOLVIMENTO DO NORDESTE - SUDENE -. Dados

pluviométricos mensais do Nordeste. 1990. Disponível em: http://www.sudene.gov.br/. Acesso em: 14 jun. 2012.

VALVERDE, T.; HERNÁNDEZ-ROSAS, L.; BERNAL, R. Habitat preference of the epiphyte
Tillandsia recurvata (Bromeliaceae) in a semidesert environment in Central Mexico Canadian. Journal of Botany, v. 83, n. 10, p.1238-1247, 2005.

WAECHTER, J.L. Epífitos vasculares da mata paludosa do Faxinal, Torres, Rio Grande do Sul, Brasil. Iheringia Série Botânica, v.34, n.1, p.39-49, 1986.

WAECHTER, J. L. O epifitismo vascular na planície costeira do Rio Grande do Sul. 1992. 13f. Tese (Doutourado em Ecologia e Recursos Naturais) - Universidade Federal de São Carlos, São Carlos, 1992.

WAECHTER, J. L. O epifitismo vascular em uma floresta de restinga do Brasil subtropical.

Revista Ciência e Natura, v.20, n.1, p.4366,1998 .

WERNECK M.D.; ESPIRITO-SANTO M.M.D. Species diversity and abundance of vascular epiphytes on Vellozia piresiana in Brazil. Biotropica, v.34, n.1, p.51-57, 2002.

ZAR, J.H. Bioestatistical analysis. New Jersey: Prentice Hall, 1999. 663p. 